\title{
Incidental finding of Meckel's diverticulum in an umbilical hernia in a 60-year-old man
}

This article was published in the following Dove Press journal:

Open Access Surgery

7 November 2012

Number of times this article has been viewed

\section{Filza Naveed \\ Daniel Passeri \\ Aaron Ilano}

Department of Surgery, St Vincent's Medical Center, Bridgeport, CT, USA
Correspondence: Daniel Passeri Department of Surgery St Vincent's Medical Center, 2800 Main Street Bridgeport, CT 06606, USA Email d.passeri@gmail.com
Abstract: Meckel's diverticulum is an outpouching in the wall of the intestine. Although it is the most common congenital abnormality of the gastrointestinal tract, diagnosing and deciding on intervention is often a matter of debate when it presents asymptomatically. A 60-year-old man with an umbilical hernia presented to our institution for elective surgery. A Meckel's diverticulum was incidentally discovered perioperatively and removed. Although the mortality and risk of complications are low, the surgical team in this case decided to remove the diverticulum to prevent any possible complications from occurring in the future due to its presence.

Keywords: Meckel's diverticulum, umbilical hernia, surgery

\section{Introduction}

Meckel's diverticulum is found in approximately $2 \%$ of the population and is the most common congenital abnormality of the gastrointestinal system. It is formed when the omphalomesenteric duct fails to obliterate by the 7 th week of gestation, resulting in developmental remnants being left behind. ${ }^{1}$ Meckel's diverticulum is more often diagnosed in males because complications are more frequently seen among men. ${ }^{2}$ In cases of symptomatic Meckel's diverticulum, patients may present with abdominal pain, cramping, nausea, vomiting, or rectal bleeding which mimics several other gastrointestinal disorders, thereby making it difficult to diagnose. In children, Meckel's diverticulum most commonly leads to lower gastrointestinal bleeding, but in adults more commonly leads to intestinal obstruction. However, many people with Meckel's diverticulum are asymptomatic, leading to incidental findings during abdominal surgery, as in the present case. There has been much controversy and debate regarding whether or not to remove asymptomatic Meckel's diverticulum found incidentally during surgery. However, it has been shown that performing an ileal resection allows removal of damaged tissue, inflammation, and ectopic tissue, thereby preventing any additional torsion or obstruction, ${ }^{3}$ as was done in the patient described here.

\section{Case report}

The patient was a 60-year-old Caucasian male who arrived at our medical center for hernia repair after being diagnosed with a ventral umbilical hernia a few weeks prior to arrival. He denied any pain but felt some tenderness and pressure localized to the area of the umbilicus, along with an obvious midline umbilical protrusion. He did not have a history of previous hernias. He denied any nausea, vomiting, fever, or chills. He reported no changes in his bowel habits, and no colicky pain was present. 
The patient had a past medical history of hypertension, obesity, and dyslipidemia. His family history was not contributory. The patient was not in any acute distress on physical examination. Examination of the heart and lungs was unremarkable. Abdominal examination revealed a small tender umbilical mass. The rest of the abdomen felt soft and nontender, and there was no distension or guarding. Bowel sounds were present. Rectal examination was unremarkable. The patient's complete blood count was within the normal range and showed a white cell count of 5300 cells $/ \mu \mathrm{L}$, hemoglobin of $14.4 \mathrm{~g} / \mathrm{dl}$, hematocrit of $44.4 \%$, and a platelet count of $206 / \mathrm{mm}^{3}$. His basic metabolic panel was also within normal range.

After adequate anesthesia was obtained, an elliptical incision was made to remove the thin umbilical skin and dissected down to the fascia where the en bloc excision of the hernia sac, adipose tissue, and skin were removed. During an attempt to clean off the fascia, it was noted that there were some adhesions in the intraperitoneal cavity which were lysed, but there was a piece of small bowel that was adherent to the inferior aspect. Dissecting the small bowel carefully, it was noted that it was quite adherent, and when we totally dissected it free, it was noted that rather than being a piece of small bowel, it was a very large Meckel's diverticulum which was attached to adhesions on the fascia near the site of the hernia. Therefore, the other adhesions were lysed so that we could mobilize the intestine and diverticulum and safely transect the Meckel's diverticulum. The bowel was then placed back inside the peritoneal cavity, and the wound was closed with 1-0 Dexon sutures to the fascia, 3-0 Dexon to the subcutaneous tissue, and 4-0 nylon to the skin.

Gross description of the resected small intestine revealed a diverticulum lined by tan-red mucosa with normal folds and a small amount of organic material. Microscopic evaluation revealed normal small bowel architecture and enterochromaffin cells (see Figure 1A and B). No ectopic or heterotopic tissue was present.

\section{Discussion}

The management and treatment of an incidental finding of Meckel's diverticulum has remained controversial and a matter of much debate. Generally, when Meckel's diverticulum is detected on imaging, it is left alone and no treatment is necessary. However, in a child or young adult, it is often excised. Other reasons for excision include local inflammation, the presence of ectopic tissue, and ulceration or perforation. The risk of mortality in a patient with a Meckel's diverticulum is $0.001 \%$. Although it is rarely a
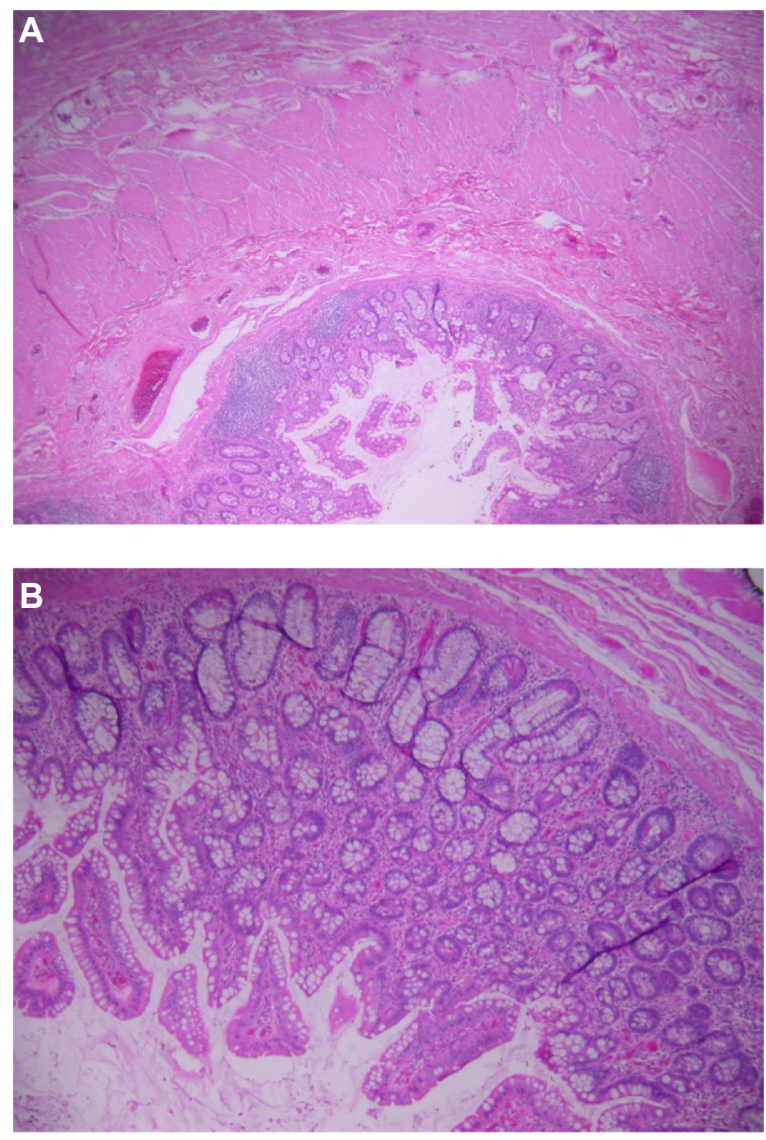

Figure I (A) Normal small bowel architecture with the presence of a true diverticulum. (B) Three layers of the lining of the lumen, ie, muscularis externa, submucosa, and villus.

Note: Enterochromaffin cells are located in the crypts.

cause of complications when diagnosed late in life, the risk of complications remains at about $4 \%-6 \% .{ }^{2}$ These complications can include malignancy, including sarcoma, carcinoma, and adenocarcinoma. ${ }^{2}$ Although there was no ectopic tissue seen in the present study, the presence of ectopic tissue which is most commonly gastric or pancreatic in origin, can lead to highly acidic secretions causing ulcerations or hemorrhage. ${ }^{4}$ They can also cause intestinal obstruction and umbilical fistulae. ${ }^{2}$ For these reasons, many surgeons consider resection whenever a Meckel's diverticulum is found incidentally during surgery in order to prevent such an event from occurring, even in asymptomatic patients. ${ }^{5}$ However, other studies have suggested that asymptomatic Meckel's diverticulum, especially when found in older patients, should be left alone to decrease the risk of postoperative complications, as well as the risk of it becoming symptomatic.

The present case supports the decision to remove Meckel's diverticulum when discovered incidentally during surgery. In this patient, the Meckel's diverticulum found within the umbilical hernia was removed through an ileal 
resection. This was done in order to eliminate the risk of it becoming symptomatic and thus having complications due to the fact that the diverticulum was manipulated with minimal trauma, which could otherwise result in inflammation and edema. Although pathology did not report the presence of any ectopic or heterotopic tissue in this case, about $60 \%$ of Meckel's diverticula present with ectopic or heterotopic tissue, and thus prophylactic diverticulectomy should be performed in order to reduce the risks of ulceration and malignancy. ${ }^{2}$

\section{Disclosure}

The authors report no conflicts of interest in this work.

\section{References}

1. Mackey WC, Dineen P. A fifty-year experience with Meckel's diverticulum. Surg Gynecol Obstet. 1983;156:56-64.

2. Cullen JJ, Kelly KA, Moir CR, Hodge DO, Zinsmeister AR, Melton LJ 3d. Surgical management of Meckel's diverticulum. An epidemiologic, population-based study. Ann Surg. 1994;220:564-569.

3. Williams RS. Management of Meckel's diverticulum. Br J Surg. 1981; 68:477-480.

4. Artigas V, Calabuig R, Badia F, Rius X, Allende L, Jover J. Meckel's diverticulum: value of ectopic tissue. Am J Surg. 1986;151:631-634.

5. Tauro LF, George C, Rao BS, Martis JJ, Menezes LT, Shenoy HD. Asymptomatic Meckel's diverticulum in adults: is diverticulectomy indicated? Saudi J Gastroenterol. 2010;16:198-202.
Open Access Surgery

\section{Publish your work in this journal}

Open Access Surgery is an international, peer-reviewed, open access journal that focuses on all aspects of surgical procedures and interventions. Patient care around the peri-operative period and patient outcomes post surgery are key topics. All grades of surgery from minor cosmetic interventions to major surgical procedures are covered. Novel techniques

\section{Dovepress}

and the utilization of new instruments and materials, including implants and prostheses that optimize outcomes constitute major areas of interest. The manuscript management system is completely online and includes a very quick and fair peer-review system. Visit http://www.dovepress.com/ testimonials.php to read real quotes from published authors. 